\title{
Graphene-cellulose tissue composites for high power supercapacitors
}

\begin{abstract}
Flexible supercapacitors have aroused a great deal of interest for their integration in portable, flexible and wearable electronic devices. In this context, graphene has emerged as an excellent building block for the fabrication of flexible electrodes. However, free-standing graphene films suffer from a certain lack of mechanical resistance, which limits their use. In this paper, we report on the fabrication of free-standing and flexible composites with enhanced robustness, consisting of a graphene layer deposited over a porous cellulose tissue. The coated graphene consists of two types of holey graphene units (i.e. wrinkled graphene sheets and graphene nanoscrolls) that produce closely interconnected and porous 3D graphene architectures. The graphene-tissue composites developed here have a thickness of around $60 \mu \mathrm{m}$ and areal densities in the $0.6-2.4 \mathrm{mg} \mathrm{cm}^{-2}$ range. These composites have a very open structure that provides easy access to the electrolyte, thereby guaranteeing high ion-transport rates. In consequence, they show a remarkable capacitive performance in both liquid $\left(1 \mathrm{M} \mathrm{H}_{2} \mathrm{SO}_{4}\right)$ and solid $\left(\mathrm{PVA}-\mathrm{H}_{2} \mathrm{SO}_{4}\right)$ electrolytes. The supercapacitors assembled with these materials possess an areal capacitance of up to $\sim 80 \mathrm{mF} \mathrm{cm}{ }^{-2}$ at low rates in both kinds of electrolyte and around $60 \mathrm{mF}$ $\mathrm{cm}^{-2}$ at $500 \mathrm{~mA} \mathrm{~cm}^{-2}$ in $\mathrm{H}_{2} \mathrm{SO}_{4}$ and $54 \mathrm{mF} \mathrm{cm}^{-2}$ at ca. $80 \mathrm{~mA} \mathrm{~cm}$ in a gel electrolyte. What is more, these SCs are able to deliver ca. $9 \mu \mathrm{Wh} \mathrm{cm}^{-2}$ of energy at a high power density of $100 \mathrm{~mW} \mathrm{~cm}^{-2}$.
\end{abstract}

Keywords: graphene, cellulose, flexible, free-standing, supercapacitors. 


\section{Introduction}

Flexible energy storage devices have attracted increasing attention for use in foldable electronic equipment (i.e. flexible phones and tablets) and also as components of wearable products (i.e. clothes, bags, etc.) [1-3]. Among energy storage systems, supercapacitors (SCs) have aroused special interest as they serve as supplementary devices for conventional or advanced batteries in a wide range of fields. The importance of SCs is due to the fact that they satisfy several important requirements such as high power, fast charge/discharge and a long cycle life. The construction of flexible SCs requires advanced electrodes that combine a high electrochemical performance with good mechanical properties such as resistance under folding and bending, compactness and light weight [4-6].

Because of its unique properties, graphene has emerged as an important building block for the fabrication of electrodes for energy storage systems such as supercapacitors and Li-ion batteries [7-9]. The singular structure of the graphene sheets makes them suitable for assembling free-standing thin films that combine an excellent flexibility with a good electrical conductivity. They are therefore well suited to acting as electrodes in flexible energy storage systems [10-13]. However, the poor mechanical strength of these thin graphene films (thickness $<50 \mu \mathrm{m}$ ), makes them difficult to handle. Therefore, the development of synthesis procedures that improve the mechanical properties of graphenebased flexible electrodes without sacrificing their electrochemical performance is clearly needed. The strategy commonly applied to materials that either have poor mechanical properties or are unable to form free-standing films is to deposit the active substances onto substrates (i.e. plastics, felts, papers, 
fabrics, etc.) that provide the necessary mechanical strength. This approach has been employed to fabricate flexible electrode composites containing a variety of electroactive substances such as nanotubes on PET [14], $\mathrm{ZnCo}_{2} \mathrm{O}_{4}$ nanowire arrays on carbon cloth [15], graphite on Xerox paper [16], activated carbon particles on different types of fabric (e.g. cotton, polyester, nylon) [17], $\mathrm{MnO}_{2}$ nanoparticles on carbon fabric $[18,19]$ or $\mathrm{NiCo}_{2} \mathrm{O}_{4}$ nanowires grown on carbon textiles [20]. Similarly, to facilitate the handling and improve the mechanical properties of graphene films, their deposition on a variety of substrates has been investigated. These include polyester fibers [21], carbon cloth [22], cotton fabrics [23-26], and cellulose-based materials such as fibers [27], filters [28] or tissues [29]. Most of the synthesis procedures involve impregnating a cellulose-based hydrophilic substrate with an aqueous dispersion of graphene oxide, which is then reduced in a subsequent step [2426, 29]. However, this methodology has two important drawbacks: a) the impregnation step needs to be repeated many times (up to 50 [26]) in order to attain a significant graphene mass loading and b) the areal energy and power densities are very low because the deposited graphene layer cannot be too thick so as to preserve the rate capability of the SC. Then, an improvement of the synthesis procedure that permits to deposit a relatively thick well-bound porous graphene layer over the cellulose substrate, would lead to highperformance graphene-cellulose composites. In this work, we present a simple synthesis strategy for assembling porous graphene sheets over a common cellulose tissue. In a first step, graphene sheets with abundant basal pores were produced by oxidizing a graphene aerogel with hydrogen peroxide. Afterwards, a graphene-cellulose composite was obtained by the vacuum 
filtration of the oxidized graphene suspension through the cellulose tissue. It should be noted that the oxidized porous graphene sheets contain numerous oxygen functional groups which are able to interact with the highly functionalized cellulose fibers, thereby ensuring that there is a strong bond between both of these components. The areal density of the graphene deposited onto the tissue can be easily controlled by adjusting the volume of the oxidized graphene suspension. In this way, flexible graphene-cellulose films with graphene loadings in the $0.5-2.5 \mathrm{mg} \mathrm{cm}^{-2}$ range and a thickness of around 50-60 $\mu \mathrm{m}$, are obtained. More significantly, the supercapacitors fabricated with these graphene-tissue composites exhibit a high areal capacitance (ca. $60 \mathrm{mF}$ $\mathrm{cm}^{-2}$ ) at current densities as high as $500 \mathrm{~mA} \mathrm{~cm}^{-2}\left(200 \mathrm{~A} \mathrm{~g}^{-1}\right)$, an excellent rate performance $\left(71 \%\right.$ retention at $500 \mathrm{~mA} \mathrm{~cm}{ }^{-2}$ ) and a long cycle life (95\% retention after 5000 cycles). They are also able to deliver a large amount of energy (ca. $9 \mu \mathrm{Wh} \mathrm{cm}^{-2}$ ) at a high power density $\left(100 \mathrm{~mW} \mathrm{~cm}^{-2}\right)$. Moreover, we have demonstrated the successful integration of the graphene-tissue composite in a solid-state flexible supercapacitor.

\section{Materials and methods}

2.1. Fabrication of the flexible graphene-tissue composite

Graphene oxide (GO) was prepared from graphite flakes (Aldrich) by using a modified Hummers method as reported elsewhere [30]. The GO solid was dispersed in water by ultrasonication (Sonics, Ultrasonic Vivracell, 500 W, $40 \%$ ) for $1.5 \mathrm{~h}$ to form a $\mathrm{GO}$ aqueous dispersion with a concentration that was adjusted to $0.5 \mathrm{mg} \mathrm{GO} \mathrm{mL} \mathrm{m}^{-1}$. Next, in order to prepare an aqueous graphene colloidal suspension, $0.24 \mathrm{~mL}$ hydrazine (35 wt \% in water, Aldrich) and 0.42 $\mathrm{mL}$ ammonia (30 wt \%, Aldrich) were added to $120 \mathrm{~mL}$ of $\mathrm{GO}$ dispersion $(0.5$ 
$\left.\mathrm{mg} \mathrm{mL}^{-1}\right)$. The mixture was stirred for $15 \mathrm{~min}$ and then treated at $100{ }^{\circ} \mathrm{C}$ for $3 \mathrm{~h}$ [31]. The as-formed graphene dispersion contained in a Teflon vessel was directly immersed in nitrogen liquid in order to obtain a high freezing rate. The frozen dispersion was placed in a lyophilizer (Telstar Cryodos) and freeze-dried at a temperature of $-51{ }^{\circ} \mathrm{C}$ and at a pressure of 0.06 mbar. In this way, a graphene aerogel with a density $<1 \mathrm{mg} \mathrm{cm}^{-3}$ was obtained. In a typical synthesis procedure for a graphene-tissue composite, around $30 \mathrm{mg}$ of graphene aerogel was dispersed in an aqueous solution of 3 wt $\% \mathrm{H}_{2} \mathrm{O}_{2}$ and then treated under reflux for $4 \mathrm{~h}$. The resultant graphene dispersion was vacuum filtrated through a tissue layer (Kleenex, thickness: $40 \mu \mathrm{m}$, areal density: $\left.1.4 \mathrm{mg} \mathrm{cm}^{-2}\right)$ placed over a regenerated cellulose membrane $(0.45 \mu \mathrm{m}$, Sartorius) and, then dried at $50{ }^{\circ} \mathrm{C}$ overnight. Finally, the graphene-tissue composite was peeled off from the membrane. In this way, graphene-tissue composites with variable graphene loadings of $0.6 \mathrm{mg} \mathrm{cm}^{-2}$ (GT-1), $1.2 \mathrm{mg} \mathrm{cm}^{-2}$ (GT-2) and $2.4 \mathrm{mg} \mathrm{cm}^{-2}$ (GT-3) were prepared. An un-oxidized graphene-tissue composite (GT-0) was also prepared under the same conditions for comparison.

\subsection{Material Characterization}

Scanning electron microscopy (SEM) images were obtained on a Quanta FEG650 (FEI) instrument, whereas transmission electron microscopy (TEM) images were recorded on a JEOL (JEM 2100-F) apparatus operating at $200 \mathrm{kV}$. The specific surface area was determined by the methylene blue adsorption method described by McAllister et al. [32]. X-ray diffraction (XRD) patterns were obtained on a Siemens D5000 instrument operating at $40 \mathrm{kV}$ and $20 \mathrm{~mA}$, using $\mathrm{Cu}$ KR radiation. The Raman spectra were recorded on a Horiva (LabRam HR-800) spectrometer. The source of radiation was a laser operating 
at a wavelength of $514 \mathrm{~nm}$ and at a power of $25 \mathrm{~mW}$. X-ray photoelectron spectroscopy (XPS) was carried out on a Specs spectrometer, using Mg KR $(1253.6 \mathrm{eV})$ radiation from a double anode at $150 \mathrm{~W}$.

The specific surface area was measured by using the methylene blue (MB) adsorption method [32]. The test was performed by dispersing (using an orbital stirrer) a known mass of the composite in a known volume of a MB solution of standard concentration (in a closed vessel) until reaching the adsorptiondesorption equilibrium of MB. The amount of MB adsorbed was determined by analyzing the supernatant through UV-Vis spectroscopy at a wavelength of 665 $\mathrm{nm}$ and subtracting the initial standard concentration. The literature value of $2.54 \mathrm{~m}^{2}$ of surface covered per $\mathrm{mg}$ of $\mathrm{MB}$ adsorbed was the basis for our calculations [32].

\subsection{Characterization of the electrochemical supercapacitors}

The electrochemical measurements were performed in two-electrode Swagelok ${ }^{\mathrm{TM}}$ type cells using $1 \mathrm{M} \mathrm{H}_{2} \mathrm{SO}_{4}$ as electrolyte. The electrochemical capacitors were assembled using two pieces of graphene-tissue composites of comparable mass and thickness, electrically isolated by a glassy fibrous separator. The electrochemical characterization was performed using a computer-controlled potentiostat (Biologic VMP3 multichannel generator). It consisted of electrochemical impedance spectroscopy studies, cyclic voltammetry experiments and galvanostatic charge/discharge cycling tests.

Electrochemical impedance spectroscopy (EIS) measurements were performed at open circuit voltage (i.e. $0 \mathrm{~V}$ ) in discharged state within the frequency range of $1 \mathrm{mHz}$ to $100 \mathrm{kHz}$ and a $10 \mathrm{mV} \mathrm{AC}$ amplitude. Bode plots of the dependence of the capacitance on frequency and Nyquist plots were 
recorded to characterize the impedance of the tested samples. The specific gravimetric capacitance of the supercapacitor, $C_{E I S}\left(F g^{-1}\right)$, was calculated according to the following formula and normalized with respect to the highest specific gravimetric capacitance, i.e. capacitance at $1 \mathrm{mHz}$ :

$$
C_{E I S}=\frac{2 \cdot \mid \operatorname{Im}(Z)}{2 \pi f\left[(\operatorname{Im}(Z))^{2}+(\operatorname{Re}(Z))^{2}\right] \cdot m}
$$

where $f$ is the operating frequency $(\mathrm{Hz}), \operatorname{Im}(Z)$ and $\operatorname{Re}(Z)$ are the imaginary and real components of the total device resistance $(\mathrm{Ohm})$, and $\mathrm{m}$ is the total mass of graphene in the supercapacitor. The relaxation time constant, $\tau_{0}$, which separates the capacitive and the resistive behavior of the supercapacitor, was deduced from the frequency $f_{0}$ as follows: $\tau_{0}=1 / f_{0}$, where $f_{0}$ is obtained from the real capacitance plot at $C^{\prime}=\mathrm{C}_{1 \mathrm{mHz}} / 2$.

Cyclic voltammetry experiments (CVs) were performed between 0 and 1.1 $\mathrm{V}$ in $\mathrm{H}_{2} \mathrm{SO}_{4}$ at increasing sweep rates from $1 \mathrm{mV} \mathrm{s}^{-1}$ to $30 \mathrm{~V} \mathrm{~s}^{-1}$. Plots of cell areal capacitance vs. voltage were calculated using the formula:

$$
\mathrm{C}_{\text {cell }}=\frac{\mathrm{I}}{v \mathrm{~S}}
$$

where $\mathrm{I}=$ current, $\quad=$ scan rate and $\mathrm{S}=$ geometrical area of the device .

Galvanostatic charge/discharge cycling (CD) was performed in the same voltage range at increasing current densities from 0.1 to $1200 \mathrm{~mA} \mathrm{~cm}^{-2}$, based on the active mass of one electrode. The cell areal capacitance determined from the galvanostatic cycles was calculated by means of the formula:

$$
\mathrm{C}_{\text {cell }}=\frac{\mathrm{I}}{(\mathrm{dV} / \mathrm{dt}) \mathrm{S}}
$$


where $d V / d t=$ the slope of the discharge curve. Taking into account the dependence of specific capacitance on the voltage in the present materials due to the presence of pseudocapacitance, the selection of an appropriate voltage range for the determination of the slope is very important to avoid overestimating the specific capacitance. As most supercapacitors are operated in the range of $V_{\max }$ to approximately $1 / 2 V_{\max }$, the upper half of the discharge curve was used to determine the slope of the discharge curve [33].

To trace the Ragone-like plots, the areal energy $\left(\mu \mathrm{Wh} \mathrm{cm}{ }^{-2}\right)$ and power $\left(\mathrm{mW} \mathrm{cm}{ }^{-2}\right)$ densities were calculated using the following formulae:

$$
\begin{aligned}
& \mathrm{E}=\frac{1}{2} \mathrm{C}_{\text {cell }} \Delta \mathrm{V}_{\mathrm{d}}^{2} \\
& \mathrm{P}=\frac{\mathrm{E}}{\Delta \mathrm{t}_{\mathrm{d}}}
\end{aligned}
$$

where $\Delta V_{d}$ is the operation voltage $\left(V_{\max }-I R_{d r o p}\right)$ and $\Delta_{t d}$ is the discharge time.

\subsection{Fabrication of flexible solid-state supercapacitors}

First, the PVA/ $\mathrm{H}_{2} \mathrm{SO}_{4}$ gel electrolyte was prepared by mixing $1 \mathrm{~g}$ of PVA (MW: $<10,000$, Aldrich) with $10 \mathrm{~mL} 1 \mathrm{M} \mathrm{H}_{2} \mathrm{SO}_{4}$. The mixture was heated at 85 ${ }^{\circ} \mathrm{C}$ under continuous stirring until the solution became transparent (around 30 $\min$ ). After that, the pieces of graphene paper used as electrodes (size: $13 \mathrm{~mm}$ $\times 26 \mathrm{~mm}$ ) were immersed in $1 \mathrm{M} \mathrm{H}_{2} \mathrm{SO}_{4}$ and dried at room temperature. In order to assemble the solid-state device, the $\mathrm{H}_{2} \mathrm{SO}_{4}$-PVA was poured onto the glassy fibrous separator. Then, the two electrodes were attached to the separator on one side and to a graphite film acting as collector on the other. The symmetric supercapacitor was finally fabricated by sandwiching all the components 
between two flexible PET films and pressing them together, forcing the polymer gel on the separator to infiltrate into the GT.

\section{Results and discussion}

\subsection{Chemical and structural characteristics of graphene-tissue composites}

The procedure used for the fabrication of flexible graphene-tissue composites is schematically illustrated in Figure 1. A key aspect of our synthesis procedure is the use of fast cooling rates to freeze the aqueous graphene suspension. Under these conditions, the graphene aerogel (Figure 2a) obtained after the lyophilization process is made up of a large fraction of graphene scrolls (Figure 2b) combined with highly wrinkled graphene sheets (Figure 2c). Both of these graphene units are closely interconnected, giving rise to a very open architecture (see Figure 2d), which explains the ultra-low density of the graphene aerogel $\left(<0.5-1 \mathrm{mg} \mathrm{cm}^{-3}\right)$. The oxidation of the graphene aerogel with hydrogen peroxide generates a large number of nanoholes (pores) in the basal planes of the graphene units (see Figure 2e), with a size in the 2-4 $\mathrm{nm}$ range, as deduced by means of HRTEM inspection (see Figure 2f). Interestingly, the scrolled and wrinkled sheet graphene morphologies are retained after the oxidation process, as can be seen from the TEM images in Figure S1. This is important because the presence of both types of building blocks contributes to preventing aggregation (stacking) of the graphene layers once the graphene film has formed. The absence of stacking and the existence of a large number of pores in the basal plane of the graphene units suggest an efficient transport of ions throughout the entire network of the graphene film. 
The tissue used as substrate for the graphene consists of a thin layer ( 40 microns) of interwoven cellulose fibres (diameter $\sim 10$ microns) which form a very open structure with large voids that facilitate the penetration of the graphene units (see Figures $3 a$ and $3 b$ ). Once the oxidized graphene dispersion has been vacuum filtrated through the cellulose tissue, a graphene-tissue composite is formed, with a thickness of around $55 \pm 10$ microns (see Figure 3c). The filtration process is relatively quick (i.e. $<30 \mathrm{~min}$ ). This composite has an asymmetric structure. Thus, whereas a dense graphene layer is deposited over the upper side (see Figure $3 e$ ), the lower side consists of cellulose fibres closely interconnected by graphene sheets, as can be seen in Figure $3 f$. This morphology proves that during the filtration process the graphene sheets partially penetrate inside the tissue, reinforcing the graphene-tissue composite. Importantly, the graphene-tissue composite exhibits a good flexibility, as shown in Figure 3d.

The chemical properties and microstructure of the graphene-tissue composites was investigated by X-ray diffraction (XRD), Raman spectroscopy and X-ray photoelectron spectroscopy (XPS). The XRD patterns in Figure 4a reveal that, whereas the graphite oxide exhibits a sharp (002) diffraction peak at $9.5^{\circ}$ (d-spacing: $0.93 \mathrm{~nm}$ ), the graphene (non-oxidized or oxidized) deposited over the tissue exhibits a weak broad band at around $24.4^{\circ}$ ( $d$-spacing $<0.36$ $\mathrm{nm})$. Although this band is typical of amorphous carbons, herein it denotes a certain stacking of a few graphene layers. On the other hand, the Raman spectra in Figure $4 \mathrm{~b}$ reveal that the $\left(\mathrm{I}_{\mathrm{D}} / \mathrm{I}_{\mathrm{G}}\right)$ ratio, used to evaluate the degree of disordering in the graphene materials, is greater in the case of the graphenetissue composites $\left(I_{D} / I_{G} \sim 1.1\right)$ than in $G O\left(I_{D} / I_{G} \sim 0.9\right)$. This can be ascribed to 
the generation of defects resulting from the formation of basal pores, which give rise to smaller $\mathrm{sp}^{2}$ domains $[34,35]$. The oxidation with hydrogen peroxide promotes the incorporation of new oxygen groups, as can be deduced from the decrease in the $(\mathrm{C} / \mathrm{O})$ atomic ratio from ca. 7 in the case of the graphene aerogel (GT-0) to ca. 4 in the case of the oxidized graphene sample (GT-3). The presence of oxygen functional groups is important since they can enhance capacitance through their involvement in reversible redox reactions and also improve the wettability of the electrodes. The nature and distribution of the $\mathrm{O}-$ groups incorporated in the graphene sheets was further investigated by XPS (Figure 4c). The deconvoluted C1s spectrum corresponding to the graphene aerogel, GT-0, shows the presence of $\mathrm{C}=\mathrm{O}$ groups $(288.3 \mathrm{eV}, \sim 8 \%)$ and $\mathrm{O}-$ $\mathrm{C}=\mathrm{O}$ groups $(289.7 \mathrm{eV}, \sim 2 \%)$ besides the $\pi-\pi^{*}$ shake-up satellite $(291.4 \mathrm{eV}, \sim$ $2 \%), \mathrm{C} \mathrm{sp}^{2}(284.5 \mathrm{eV}, 60 \%)$ and $\mathrm{C} \mathrm{sp}{ }^{3}(285.9 \mathrm{eV}, 27.5 \%)$ [36, 37]. After oxidation, the GT-3 material also shows C-O groups at $286.8 \mathrm{eV}(8.5 \%)$ and a slight reduction $(\sim 4 \%)$ in the content of both $\mathrm{Csp}$ and $\mathrm{Csp}$. On the other hand, GO oxygen functionalities are distributed in C-O groups (286.6 eV, 52 \%) and $\mathrm{C}=\mathrm{O}$ groups $(288.1 \mathrm{eV}, 12 \%)[36,37]$.

The specific surface area of the composites, as determined by the adsorption of methylene blue dye, increases from $270 \mathrm{~m}^{2} \mathrm{~g}^{-1}$ for the un-oxidized GT-0 sample to $540 \mathrm{~m}^{2} \mathrm{~g}^{-1}$ for GT-3 (Figure 4d), as a consequence of the generation of basal nanopores. This indicates that the oxidative process enhances the area accessible to the ionic species because of the generation of new pores and probably the opening of closed cavities. 


\subsection{Electrochemical performance}

The potential of graphene-tissue composites to act as supercapacitor electrodes was assessed by assembling symmetric cells with a $1 \mathrm{M} \mathrm{H}_{2} \mathrm{SO}_{4}$ solution as electrolyte. Figure 5 a shows the $\mathrm{CVs}$ in $1 \mathrm{M} \mathrm{H}_{2} \mathrm{SO}_{4}$ at an increasing scan rate for a composite graphene-tissue with an areal density of $0.6 \mathrm{mg} \mathrm{cm}$-2 (GT-1). As can be seen, quasi-rectangular voltammograms are obtained up to $10 \mathrm{~V} \mathrm{~s}^{-1}$ (with a linear dependence of the discharge current on the scan rate as shown in Figure S2a), indicating the quick and efficient formation of the electric double-layer. Only somewhat distorted voltammograms are obtained at scan rates as high as $30 \mathrm{~V} \mathrm{~s}^{-1}$. When the areal density is doubled (i.e., GT-2, $1.2 \mathrm{mg}$ $\mathrm{cm}^{-2}$ ), a good EDLC performance is still maintained up to $5 \mathrm{~V} \mathrm{~s}^{-1}$ (see Figures S2b-c) and even with a four-fold increase in areal density (i.e., GT-3, $2.4 \mathrm{mg}$ $\mathrm{cm}^{-2}$ ), the supercapacitor is still able to keep up with scan rates as high as $2 \mathrm{~V}$ $\mathrm{s}^{-1}$ (see Figures 5b and S2b). Importantly, this four-fold increase in areal density translates directly into a four-fold increase in areal capacitance (see Figures 5ab), which suggests that this material is able to integrate both high energy and high power characteristics. This behaviour contrasts with that of the un-oxidized graphene paper (GT-0, $3 \mathrm{mg} \mathrm{cm}^{-2}$ ), whose CV curves already show a slow ion transport at scan rates of $0.2 \mathrm{~V} \mathrm{~s}^{-1}$ (see Figure S2d). This lower ion transport capability evidences the essential role of the in-plane nanoholes in the oxidized samples in promoting ion transport through the graphene sheets. This is corroborated by the Nyquist plots in Figure S3a, which show a large Warburg region in the un-oxidized graphene paper, whereas it is negligible in the oxidized samples. Thereby, GT-0 shows the slowest frequency response $\left(\tau_{0}=\right.$ 7.2 s) and, as expected, the composite with the lowest areal density, GT-1, 
exhibits the fastest response $\left(\tau_{0}=35 \mathrm{~ms}\right)$. It is also worth mentioning that previous studies on graphene deposited on different types of substrate only show capacitive behavior at scan rates of $<0.1-0.2 \mathrm{~V} \mathrm{~s}^{-1}[24-26,28,38]$.

The excellent supercapacitor performance of these graphene-tissue composites is further corroborated by constant current charge/discharge experiments. Thus, as evidenced by Figure 5c, voltage drops as low as 15, 40 and $100 \mathrm{mV}$ are recorded at an ultra-large current density of $100 \mathrm{~A} \mathrm{~g}^{-1}$ for areal densities of 0.6 (GT-1), 1.2 (GT-2) and $2.4 \mathrm{mg} \mathrm{cm}^{-2}$ (GT-3) respectively. This reflects a low equivalent series resistance $(E S R$, which varies from $0.17 \mathrm{Ohm}$

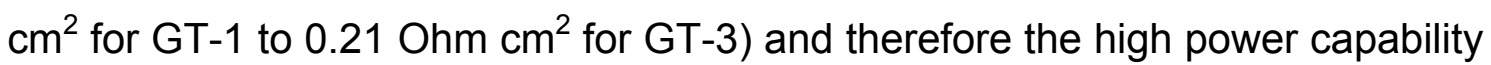
of these composites. In this regard, Figure $5 \mathrm{~d}$ shows that these graphene-tissue composites are able to operate up to current densities as high as $900-1000$ $\mathrm{mA} \mathrm{cm}{ }^{-2}$ with capacitance retentions in the range of $53-70 \%$. Especially remarkable is the performance of the supercapacitor assembled with the composite with the highest loading, GT-3, which shows areal capacitances of around $80 \mathrm{mF} \mathrm{cm}^{-2}$ at low rates and ca. $60 \mathrm{mF} \mathrm{cm}^{-2}$ at $500 \mathrm{~mA} \mathrm{~cm}$. The high rate capability of these graphene-tissue composites despite the increase in areal density is attributable to the combined effect of: i) the unique structure of the graphene paper which is made up of wrinkled graphene sheets and scrolls that greatly reduces stacking and speeds up ion diffusion across the graphene sheets, ii) the in-plane nanoholes present in the graphene units which facilitate the transport of ions through them, and c) the tissue support which facilitates impregnation by the electrolyte and acts as an electrolyte reservoir, reducing the ion diffusion distances. The integration of both high areal energy-high areal power in the supercapacitor assembled with GT-3 is confirmed in the Ragone- 
like plot in Figure 5e. Thus, this sample is able to deliver up to $14 \mu \mathrm{Wh} \mathrm{cm}{ }^{-2}$ at $0.2 \mathrm{~mW} \mathrm{~cm}^{-2}$ (vs. $\sim 7 \mu \mathrm{Wh} \mathrm{cm}{ }^{-2}$ for GT-2) and an areal energy density of $4 \mu \mathrm{Wh}$

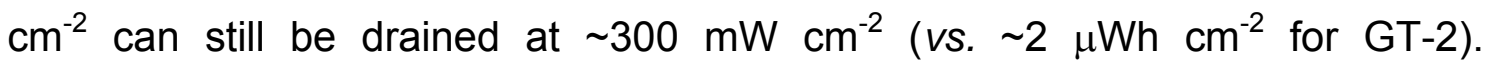
Furthermore, this material exhibits an excellent robustness, as can be seen from the small loss of capacitance (5\%) after 5000 cycles at $5 \mathrm{~A} \mathrm{~g}^{-1}$ and $1.1 \mathrm{~V}$ (see Figure 5f).

Figure 6 compares the energy and power characteristics of the GT-3 supercapacitor with those of supercapacitors based on supported graphene or hydrated graphene films reported in the literature. As can be seen, the GT-3based supercapacitor (trace A) achieves higher power densities than any of those based on supported graphene, such as graphene on cloth [26] or graphene on cellulose [28]. Furthermore, the supercapacitor can store more energy at high power densities than top-performing graphene hydrated films [39-42].

Further evaluation of the electrochemical performance of the graphenetissue composites was performed by assembling a solid-state flexible device with two identical pieces of the composite as electrodes $\left(1.9 \mathrm{mg} \mathrm{cm}{ }^{-2}\right)$ and polyvinyl alcohol (PVA)- $\mathrm{H}_{2} \mathrm{SO}_{4}$ as gel electrolyte. Figure $7 \mathrm{a}$ provides an illustration of the as-prepared flexible supercapacitor and its corresponding bending state. For details about the preparation and assembly, the reader is referred to the experimental section. The excellent performance of the graphene-tissue (GT) composites previously observed in the $\mathrm{H}_{2} \mathrm{SO}_{4}$ electrolyte is also obtained in the solid-state device. Thus, as shown in Figure 7b, cell areal capacitances of $75 \mathrm{mF} \mathrm{cm} \mathrm{cm}^{-2}$ are obtained at low current densities $\left(0.2 \mathrm{~mA} \mathrm{~cm}{ }^{-2}\right)$. This value is comparable, or superior, to the best graphene paper materials 
found in the literature $[28,43]$ and to those of other materials such as activated carbon cloths [44]. It should also be mentioned that the capacitance value measured with the gel electrolyte is very close to that of the device based on 1 $\mathrm{M} \mathrm{H}_{2} \mathrm{SO}_{4}$, which indicates an efficient infiltration of the polymer gel electrolyte into the graphene-cellulose composite (see Figure $7 \mathrm{~b}$ ). The slight divergence at low current densities can be ascribed to the difference in the electrode mass loading used for $1 \mathrm{M} \mathrm{H}_{2} \mathrm{SO}_{4}$ and the gel electrolyte $\left(2.4 \mathrm{mg} \mathrm{cm}^{-2}\right.$ and $1.9 \mathrm{mg}$ $\mathrm{cm}^{-2}$ respectively). More importantly, at high current densities $\left(76 \mathrm{~mA} \mathrm{~cm}^{-2}\right)$, the solid-state GT-supercapacitor exhibits a cell areal capacitance of $54 \mathrm{mF} \mathrm{cm}{ }^{-2}$, which indicates a capacitance retention of $72 \%$. This value is very high taking into account that such high current densities have never been reached before in solid-state devices [28, 39, 43, 45]. The lower capacitance retention of the solidstate device is attributable to its higher ESR resistance (see Figure S3a), which slows down the frequency response to $2.2 \mathrm{~s}$ (see inset in Figure S3a). This stems from the much lower ionic conductivity of the polymer gel electrolyte. Therefore, optimization of the electrolyte would enable a supercapacitor with an even higher rate capability. The stability of the solid-state supercapacitor was evaluated by long-term $C D$ at $10 \mathrm{~mA} \mathrm{~cm}^{-2}$. As can be seen in Figure $\mathrm{S} 3 \mathrm{~b}$, capacitance loss after 5000 cycles is lower than $10 \%$. In addition, the voltage profiles of the $1^{\text {st }}$ and $5000^{\text {th }}$ cycle prove that no apparent changes take place after long-term cycling. To demonstrate the toughness and the flexibility of the supercapacitor, the capacitive performance of the solid-state supercapacitor was tested at a bending angle of $45^{\circ}$ by constant current charge/discharge cycling. Figure $7 c$ shows that the voltage profile hardly changes in response to 
bending, suggesting a similar electrochemical performance to that of the unbent state.

Apart from cycling stability, another important feature of a supercapacitor is its ability to maintain its voltage under long-term storage, especially for backup applications. This feature was evaluated by measuring the leakage current and self-discharge. For the leakage current test, the solid-state device was first charged to $1.1 \mathrm{~V}$ and kept at this voltage for $2 \mathrm{~h}$. As can be seen in Figure $7 \mathrm{~d}$, the leakage current is only $\sim 10 \mu \mathrm{A} \mathrm{mg}{ }^{-1}$ after 2 hours. For the self-discharge test, the variation of the supercapacitor voltage was recorded over 48 hours at open-circuit voltage. As shown in Figure 7d, once the solid supercapacitor was charged for 2 hours at $1.1 \mathrm{~V}$, the voltage reached $1 / 2 \mathrm{~V}_{\max }$ after 13.5 hours. This change from $V_{\max }$ to $1 / 2 \quad V_{\max }$ is an important parameter since most supercapacitors operate in this range. The time recorded for this graphene material is comparable to that of other solid-state devices based on graphene hydrogel films $[39,43]$.

\section{Conclusions}

In conclusion, a novel strategy has been presented for fabricating flexible and free-standing thin composites made up of holey graphene units (i.e. wrinkled graphene sheets and graphene nanoscrolls) deposited over a porous cellulose tissue. These graphene-tissue composites exhibit a very open structure that provides easy access to the electrolyte solution, guaranteeing high ion-transport rates. When used as electrodes for supercapacitors, they show a remarkable electrochemical performance with a high areal energy density of ca. $9 \mu \mathrm{Wh} \mathrm{cm}^{-2}$ at an ultra-large areal power density of $100 \mathrm{~mW} \mathrm{~cm}^{-2}$ in $1 \mathrm{M} \mathrm{H}_{2} \mathrm{SO}_{4}$. A robust and flexible solid-state supercapacitor assembled using the composite material 
showed an enhanced capacitive performance, and an areal capacitance of 54 $\mathrm{mF} \mathrm{cm}$ at ca. $80 \mathrm{~mA} \mathrm{~cm}{ }^{-2}$ (which represents a capacitance retention of $72 \%$ for a 400 -fold increase in current density).

\section{Acknowledgments}

This research work was supported by the FICYT Regional Project (GRUPIN14102) and Spanish MINECO (CTQ2015-63552-R). G. A. F. thanks the MINECO for his predoctoral contract. 


\section{References}

[1] X. Lu, M. Yu, G. Wang, Y. Tong, Y. Li. Flexible solid-state supercapacitors: design, fabrication and applications. Energy Environ Sci 7 (2014) 2160-2181.

[2] Y.-Z. Zhang, Y. Wang, T. Cheng, W.-Y. Lai, H. Pang, W. Huang. Flexible supercapacitors based on paper substrates: a new paradigm for low-cost energy storage. Chem Soc Rev 44 (2015) 5181-5199.

[3] X. Peng, L. Peng, C. Wu, Y. Xie. Two dimensional nanomaterials for flexible supercapacitors. Chem Soc Rev 43 (2014) 3303-3323.

[4] N. Zhiqiang, L. Lili, S. Peter, C. Jun, C. Xiaodong. Flexible Supercapacitors Development of Bendable Carbon Architectures. Nanotechnology for Sustainable Energy: American Chemical Society 2013, p. 101-141.

[5] D.P. Dubal, J.G. Kim, Y. Kim, R. Holze, C.D. Lokhande, W.B. Kim. Supercapacitors Based on Flexible Substrates: An Overview. Energy Technology 2 (2014) 325-341.

[6] T. Chen, L. Dai. Flexible supercapacitors based on carbon nanomaterials. J Mater Chem A 2 (2014) 10756-10775.

[7] J. Chen, C. Li, G. Shi. Graphene Materials for Electrochemical Capacitors. J Phys Chem Lett 4 (2013) 1244-1253.

[8] X. Cao, Z. Yin, H. Zhang. Three-dimensional graphene materials: preparation, structures and application in supercapacitors. Energy Environ Sci 7 (2014) 1850-1865.

[9] Y. Xu, G. Shi, X. Duan. Self-Assembled Three-Dimensional Graphene Macrostructures: Synthesis and Applications in Supercapacitors. Acc Chem Res 48 (2015) 1666-1675.

[10] Z. Niu, L. Liu, L. Zhang, W. Zhou, X. Chen, S. Xie. Programmable Nanocarbon-Based Architectures for Flexible Supercapacitors. Adv Energy Mater 5 (2015) n/a-n/a.

[11] S. He, W. Chen. 3D graphene nanomaterials for binder-free supercapacitors: scientific design for enhanced performance. Nanoscale 7 (2015) 6957-6990.

[12] Y. Shao, M.F. El-Kady, L.J. Wang, Q. Zhang, Y. Li, H. Wang, et al. Graphenebased materials for flexible supercapacitors. Chem Soc Rev 44 (2015) 3639-3665.

[13] J. Ji, Y. Li, W. Peng, G. Zhang, F. Zhang, X. Fan. Advanced Graphene-Based Binder-Free Electrodes for High-Performance Energy Storage. Adv Mater 27 (2015) 5264-5279.

[14] L. Hu, M. Pasta, F.L. Mantia, L. Cui, S. Jeong, H.D. Deshazer, et al. Stretchable, Porous, and Conductive Energy Textiles. Nano Letters 10 (2010) 708-714.

[15] B. Liu, J. Zhang, X. Wang, G. Chen, D. Chen, C. Zhou, et al. Hierarchical Three-Dimensional ZnCo2O4 Nanowire Arrays/Carbon Cloth Anodes for a Novel Class of High-Performance Flexible Lithium-Ion Batteries. Nano Letters 12 (2012) 30053011.

[16] G. Zheng, L. Hu, H. Wu, X. Xie, Y. Cui. Paper supercapacitors by a solvent-free drawing method. Energy Environ Sci 4 (2011) 3368-3373.

[17] K. Jost, C.R. Perez, J.K. McDonough, V. Presser, M. Heon, G. Dion, et al. Carbon coated textiles for flexible energy storage. Energy Environ Sci 4 (2011) 50605067.

[18] L. Bao, X. Li. Towards Textile Energy Storage from Cotton T-Shirts. Adv Mater 24 (2012) 3246-3252.

[19] L. Yuan, X.-H. Lu, X. Xiao, T. Zhai, J. Dai, F. Zhang, et al. Flexible Solid-State Supercapacitors Based on Carbon Nanoparticles/MnO2 Nanorods Hybrid Structure. ACS Nano 6 (2012) 656-661. 
[20] L. Shen, Q. Che, H. Li, X. Zhang. Mesoporous NiCo2O4 Nanowire Arrays Grown on Carbon Textiles as Binder-Free Flexible Electrodes for Energy Storage. Adv Funct Mater 24 (2014) 2630-2637.

[21] G. Yu, L. Hu, M. Vosgueritchian, H. Wang, X. Xie, J.R. McDonough, et al. Solution-Processed Graphene/MnO2 Nanostructured Textiles for High-Performance Electrochemical Capacitors. Nano Letters 11 (2011) 2905-2911.

[22] S. Wang, B. Pei, X. Zhao, R.A.W. Dryfe. Highly porous graphene on carbon cloth as advanced electrodes for flexible all-solid-state supercapacitors. Nano Energy 2 (2013) 530-536.

[23] L. Gan, S. Shang, C.W.M. Yuen, S.-x. Jiang. Graphene nanoribbon coated flexible and conductive cotton fabric. Compos Sci Technol 117 (2015) 208-214.

[24] Q. Zhou, X. Ye, Z. Wan, C. Jia. A three-dimensional flexible supercapacitor with enhanced performance based on lightweight, conductive graphene-cotton fabric electrode. J Power Sources 296 (2015) 186-196.

[25] L.-L. Xu, M.-X. Guo, S. Liu, S.-W. Bian. Graphene/cotton composite fabrics as flexible electrode materials for electrochemical capacitors. RSC Adv 5 (2015) 2524425249.

[26] W.-w. Liu, X.-b. Yan, J.-w. Lang, C. Peng, Q.-j. Xue. Flexible and conductive nanocomposite electrode based on graphene sheets and cotton cloth for supercapacitor. $\mathrm{J}$ Mater Chem 22 (2012) 17245-17253.

[27] Y.-R. Kang, Y.-L. Li, F. Hou, Y.-Y. Wen, D. Su. Fabrication of electric papers of graphene nanosheet shelled cellulose fibres by dispersion and infiltration as flexible electrodes for energy storage. Nanoscale 4 (2012) 3248-3253.

[28] Z. Weng, Y. Su, D.-W. Wang, F. Li, J. Du, H.-M. Cheng. Graphene-Cellulose Paper Flexible Supercapacitors. Adv Energy Mater 1 (2011) 917-922.

[29] L. Liu, Z. Niu, L. Zhang, W. Zhou, X. Chen, S. Xie. Nanostructured Graphene Composite Papers for Highly Flexible and Foldable Supercapacitors. Adv Mater 26 (2014) 4855-4862.

[30] W. Lv, D.-M. Tang, Y.-B. He, C.-H. You, Z.-Q. Shi, X.-C. Chen, et al. LowTemperature Exfoliated Graphenes: Vacuum-Promoted Exfoliation and Electrochemical Energy Storage. ACS Nano 3 (2009) 3730-3736.

[31] D. Li, M.B. Muller, S. Gilje, R.B. Kaner, G.G. Wallace. Processable aqueous dispersions of graphene nanosheets. Nat Nano 3 (2008) 101-105.

[32] M.J. McAllister, J.-L. Li, D.H. Adamson, H.C. Schniepp, A.A. Abdala, J. Liu, et al. Single Sheet Functionalized Graphene by Oxidation and Thermal Expansion of Graphite. Chem Mater 19 (2007) 4396-4404.

[33] M.D. Stoller, R.S. Ruoff. Best practice methods for determining an electrode material's performance for ultracapacitors. Energy Environ Sci 3 (2010) 1294-1301.

[34] S. Stankovich, D.A. Dikin, R.D. Piner, K.A. Kohlhaas, A. Kleinhammes, Y. Jia, et al. Synthesis of graphene-based nanosheets via chemical reduction of exfoliated graphite oxide. Carbon 45 (2007) 1558-1565.

[35] Z. Lin, G. Waller, Y. Liu, M. Liu, C.-P. Wong. Facile Synthesis of NitrogenDoped Graphene via Pyrolysis of Graphene Oxide and Urea, and its Electrocatalytic Activity toward the Oxygen-Reduction Reaction. Adv Energy Mater 2 (2012) 884-888. [36] H. Darmstadt, C. Roy, S. Kaliaguine. ESCA characterization of commercial carbon blacks and of carbon blacks from vacuum pyrolysis of used tires. Carbon 32 (1994) 1399-1406.

[37] S. Biniak, G. Szymański, J. Siedlewski, A. Świtkowski. The characterization of activated carbons with oxygen and nitrogen surface groups. Carbon 35 (1997) 17991810. 
[38] A. Ramadoss, B. Saravanakumar, S.J. Kim. Thermally reduced graphene oxidecoated fabrics for flexible supercapacitors and self-powered systems. Nano Energy 15 (2015) 587-597.

[39] Y. Xu, Z. Lin, X. Huang, Y. Liu, Y. Huang, X. Duan. Flexible Solid-State Supercapacitors Based on Three-Dimensional Graphene Hydrogel Films. ACS Nano 7 (2013) 4042-4049.

[40] X. Yang, C. Cheng, Y. Wang, L. Qiu, D. Li. Liquid-Mediated Dense Integration of Graphene Materials for Compact Capacitive Energy Storage. Science 341 (2013) 534-537.

[41] Z. Xiong, C. Liao, W. Han, X. Wang. Mechanically Tough Large-Area Hierarchical Porous Graphene Films for High-Performance Flexible Supercapacitor Applications. Adv Mater 27 (2015) 4469-4475.

[42] U.N. Maiti, J. Lim, K.E. Lee, W.J. Lee, S.O. Kim. Three-Dimensional Shape Engineered, Interfacial Gelation of Reduced Graphene Oxide for High Rate, Large Capacity Supercapacitors. Adv Mater 26 (2014) 615-619.

[43] Y. Xu, C.-Y. Chen, Z. Zhao, Z. Lin, C. Lee, X. Xu, et al. Solution Processable Holey Graphene Oxide and Its Derived Macrostructures for High-Performance Supercapacitors. Nano Letters 15 (2015) 4605-4610.

[44] G. Wang, H. Wang, X. Lu, Y. Ling, M. Yu, T. Zhai, et al. Solid-State Supercapacitor Based on Activated Carbon Cloths Exhibits Excellent Rate Capability. Adv Mater 26 (2014) 2676-2682.

[45] Y. Xu, Z. Lin, X. Huang, Y. Wang, Y. Huang, X. Duan. Functionalized Graphene Hydrogel-Based High-Performance Supercapacitors. Adv Mater 25 (2013) 5779-5784. 


\section{List of Figures}

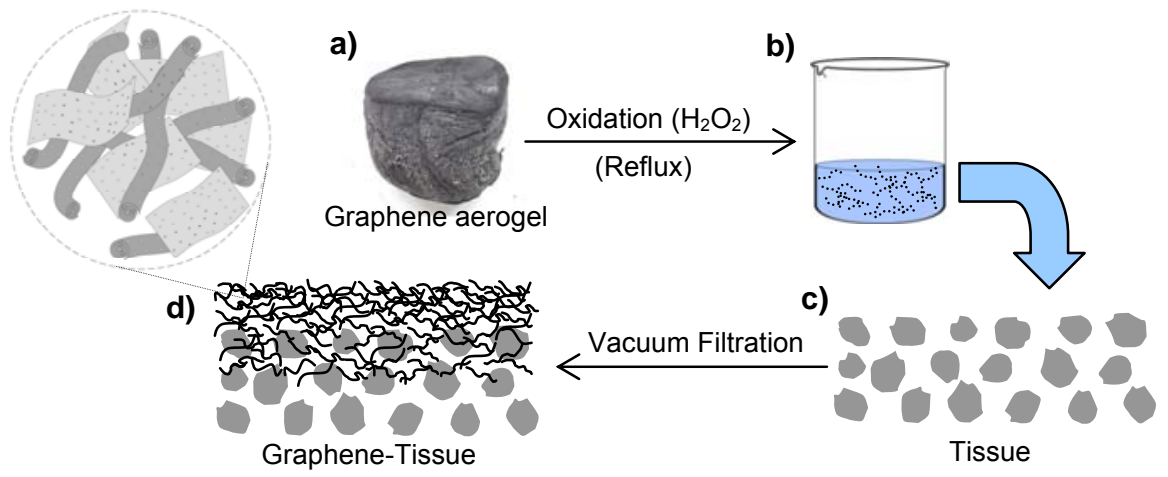

Figure 1. Schematic illustration of the synthesis procedure. (a) Graphene aerogel composed of wrinkled graphene sheets and scrolls, (b) an aqueous dispersion of porous oxidized graphene, (c) cellulose tissue and (d) a graphenetissue composite made up of a layer of porous oxidized graphene units (sheets and scrolls) deposited over a cellulose tissue. 

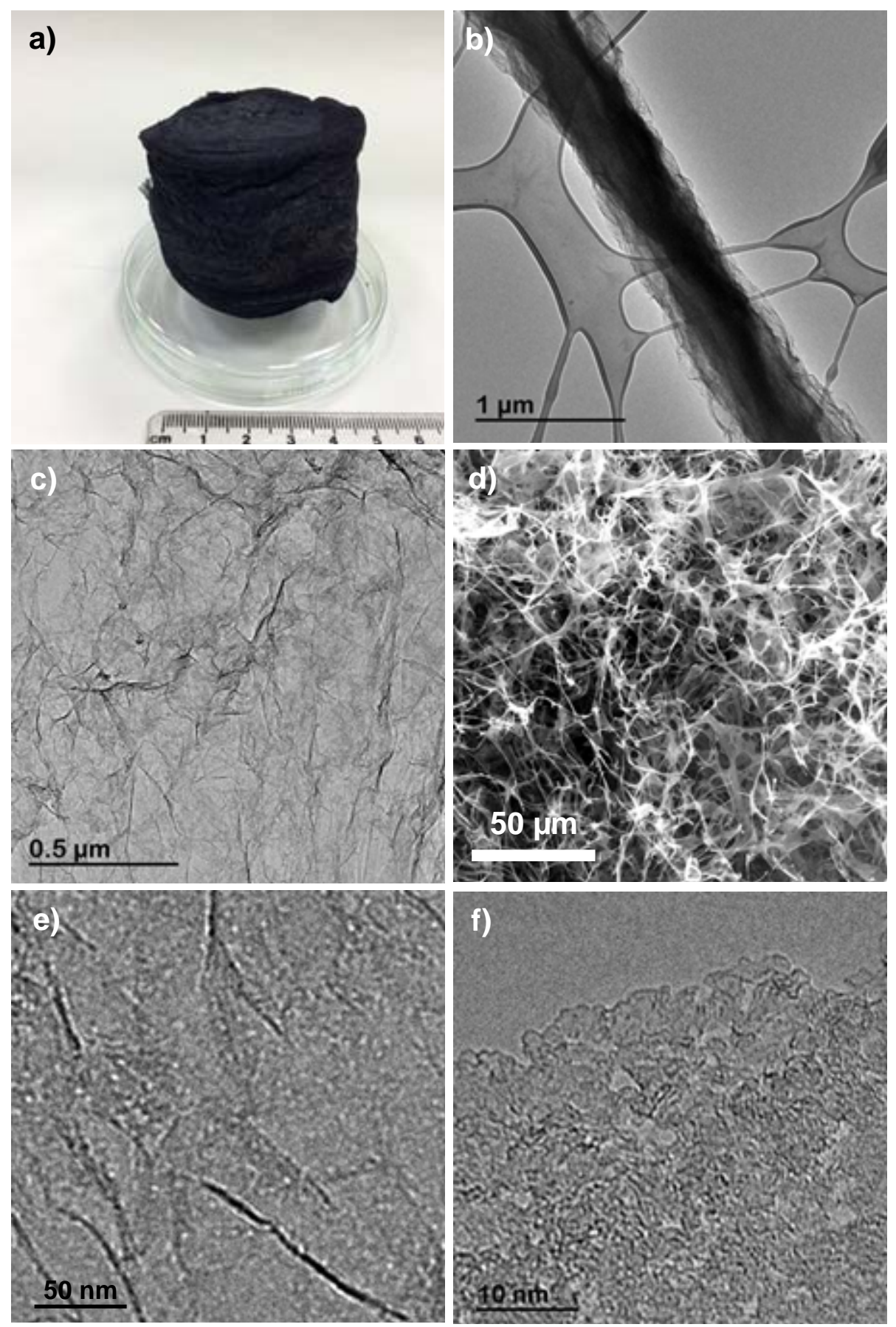

Figure 2. (a) Image of a graphene aerogel, (b) TEM image of a graphene scroll, (c) TEM image of a wrinkled graphene sheet, (d) SEM microphotograph of a graphene aerogel, (e, f) TEM images of an oxidized graphene aerogel. 

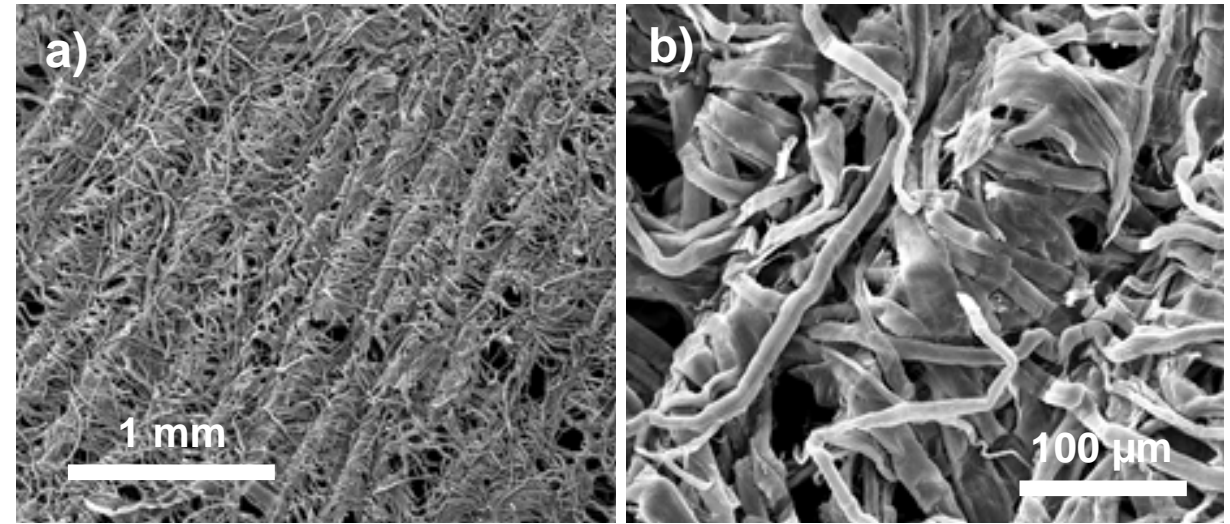

c)
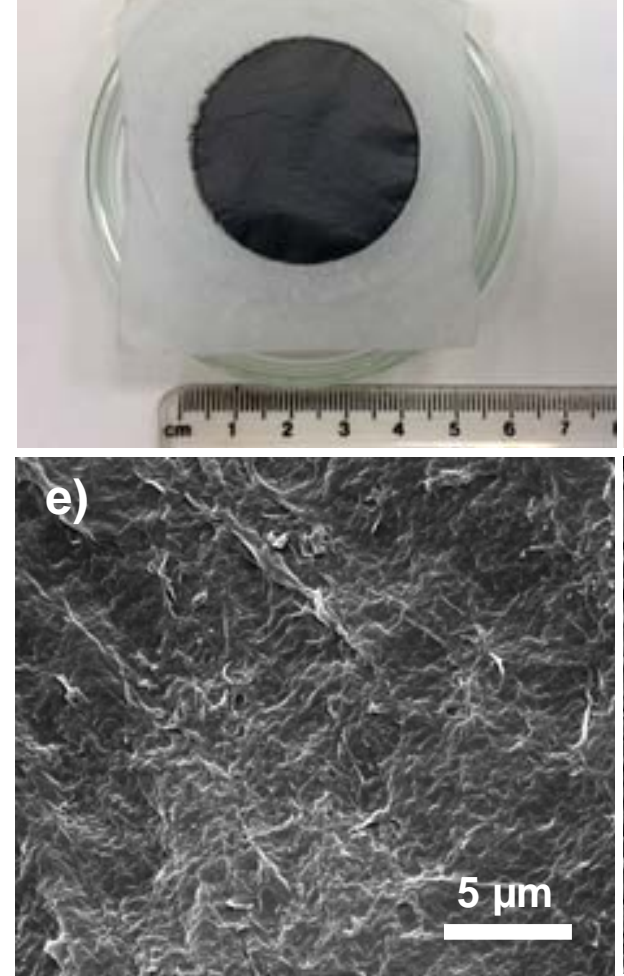

d)

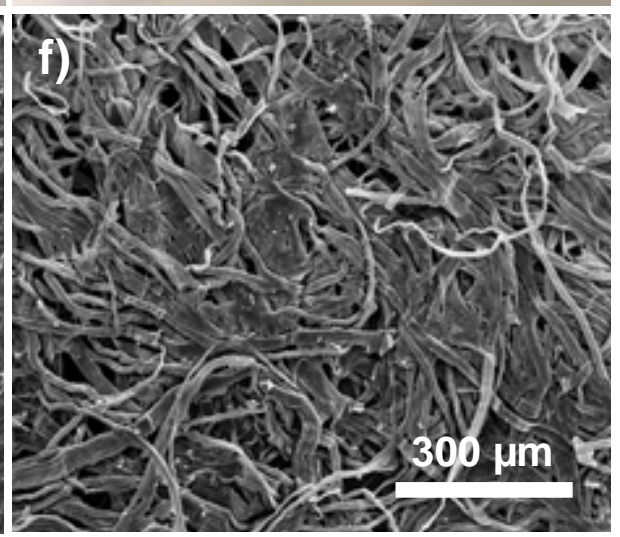

Figure 3. (a, b) SEM microphotographs of the cellulose tissue used as substrate, (c, d) images of the graphene-tissue composite and (e, f) SEM microphotographs of the graphene-tissue composite taken at the (e) upper and (f) lower sides. 

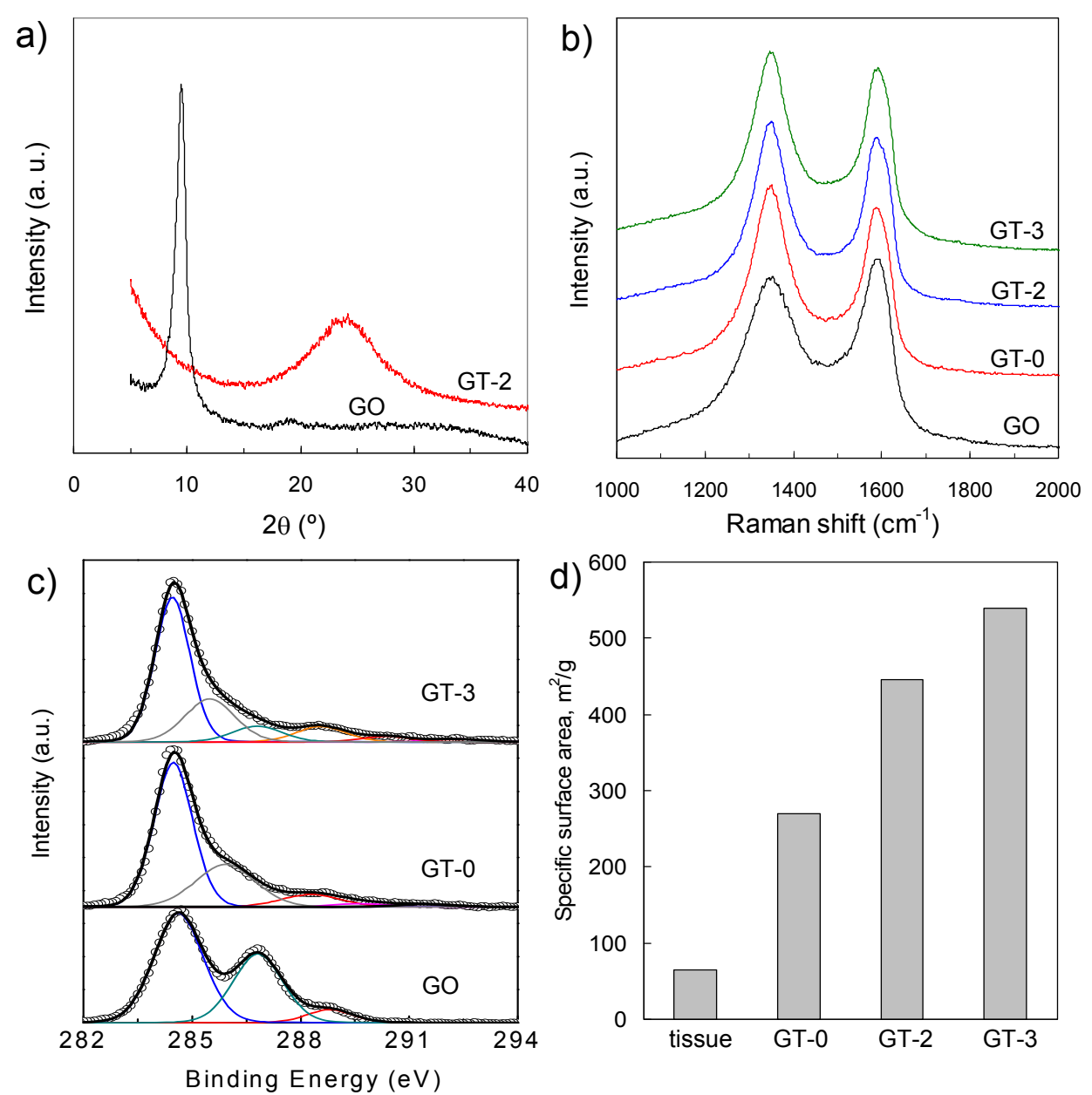

Figure 4. (a) XRD patterns, (b) Raman spectra, (c) high-resolution XPS C1s spectra of GO and of the graphene composites GT-0 and GT-3, and (d) specific surface areas of the tissue and graphene-tissue composites. 

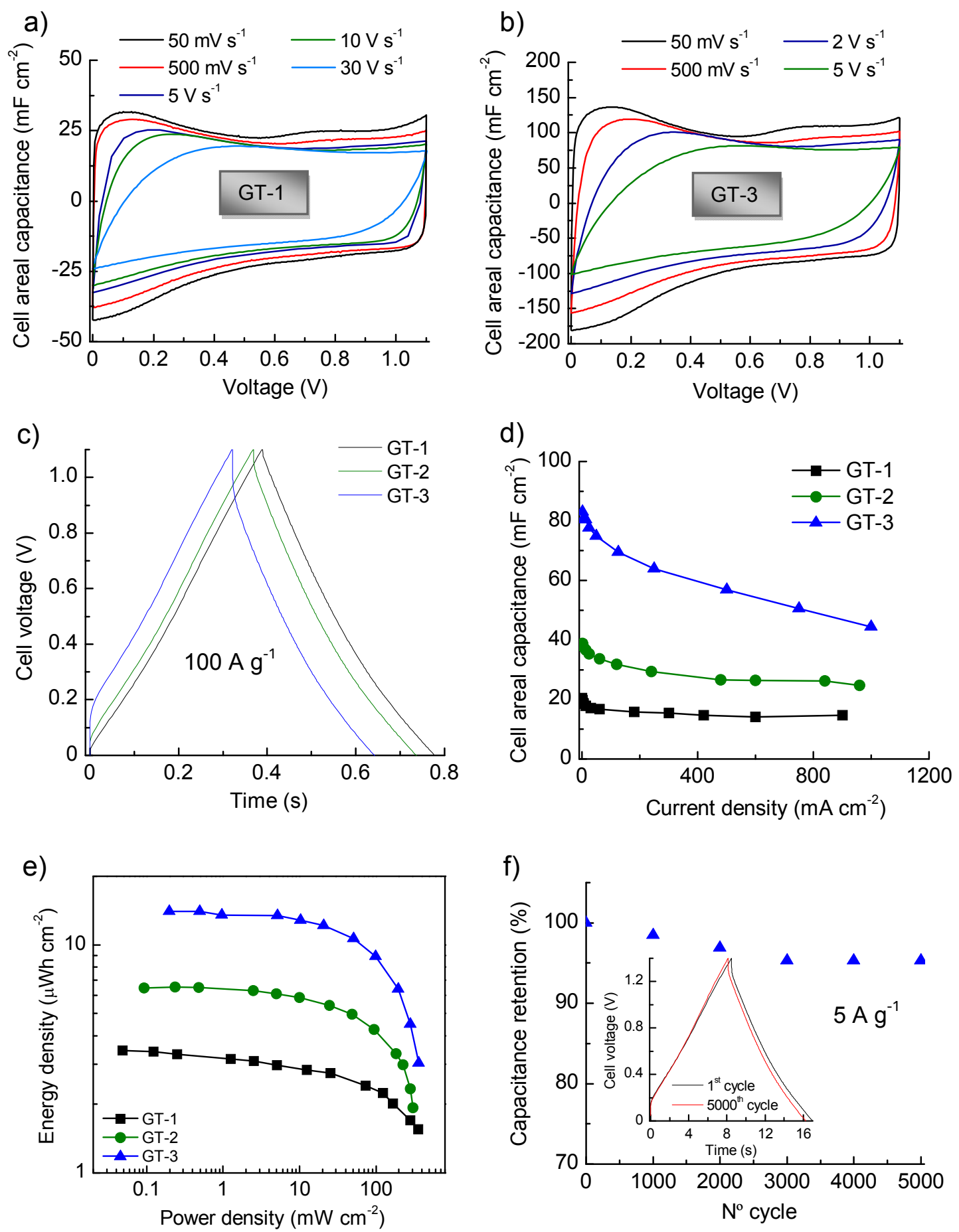

Figure 5. CVs at increasing scan rates of the supercapacitors assembled with a) GT-1 $\left(0.6 \mathrm{mg} \mathrm{cm}^{-2}\right)$ and b) GT-3 $\left(2.4 \mathrm{mg} \mathrm{cm}^{-2}\right)$ in $\left.1 \mathrm{M} \mathrm{H}_{2} \mathrm{SO}_{4}, \mathrm{c}\right)$ voltage profiles at $100 \mathrm{~A} \mathrm{~g}^{-1}$ (coulombic efficiency $\sim 99.1-99.7 \%$ ), d) rate capability evaluated by constant current charge/discharge cycling, e) Ragone-like plot and f) long-term stability evaluated by constant current charge/discharge cycling at $5 \mathrm{~A} \mathrm{~g}^{-1}$ over 5000 cycles at $1.1 \mathrm{~V}$ for the GT-3 sample (inset: initial and final voltage profiles). Electrolyte: $1 \mathrm{M} \mathrm{H}_{2} \mathrm{SO}_{4}$. 


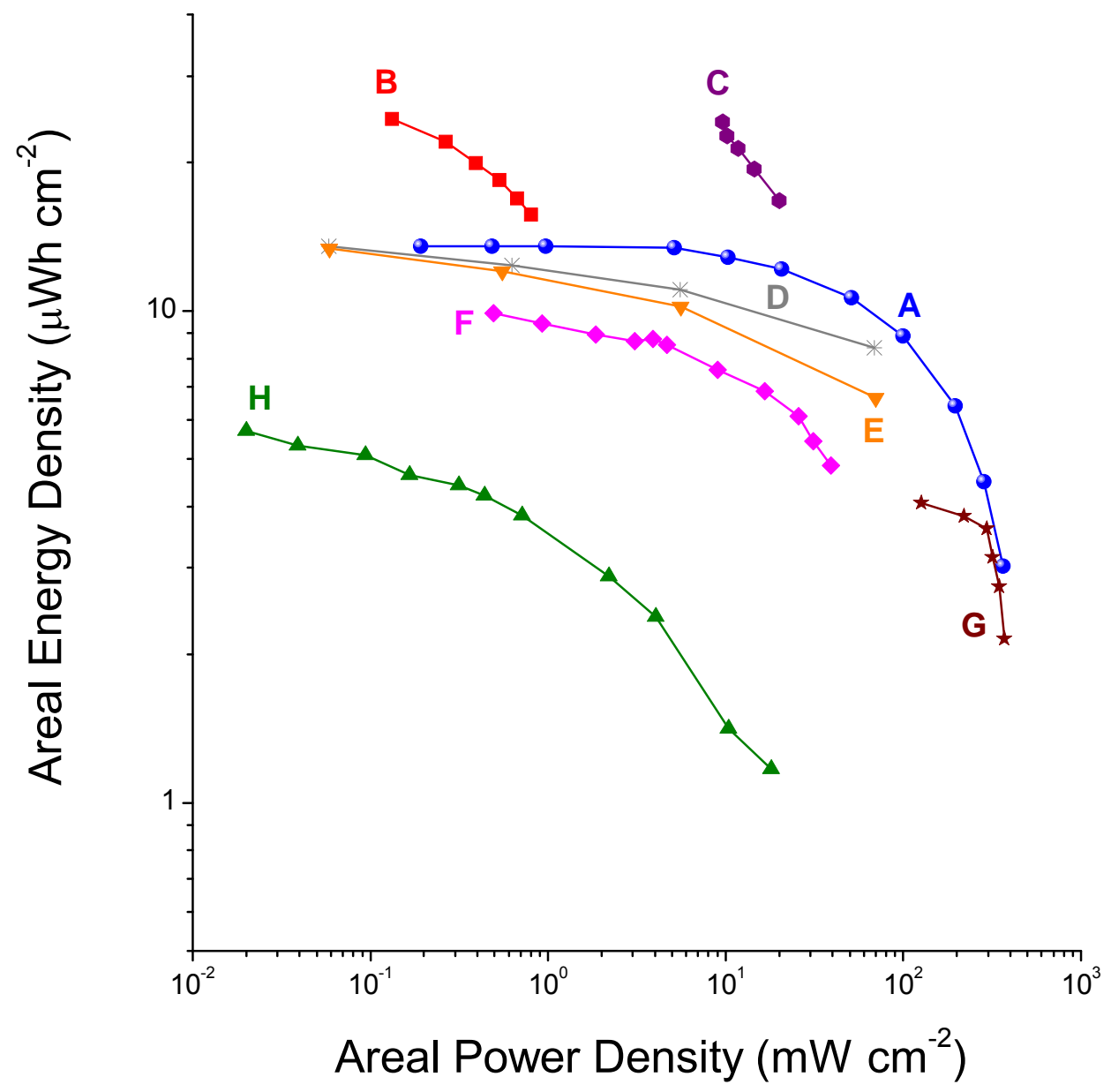

Figure 6. Ragone plot that compares the areal energy and power densities obtained for the graphene-tissue composite GT-3 (trace A, $2.5 \mathrm{mg} \mathrm{cm}^{-2}, 1 \mathrm{M}$ $\mathrm{H}_{2} \mathrm{SO}_{4}$ ) with those obtained for other graphene-based films: $B$ (graphene sheets-cotton cloth, $1.08 \mathrm{mg} \mathrm{cm}^{-2}$ ) [26], C (graphene hydrogel film, $120 \mu \mathrm{m}, 2$ $\mathrm{mg} \mathrm{cm}^{-2}$ ) [39], $D$ (chemically converted graphene hydrogel film, $1 \mathrm{mg} \mathrm{cm}^{-2}, 0.76$ $\mathrm{g} \mathrm{cm}^{-3}$ ) [40], $\mathrm{E}$ (chemically converted graphene hydrogel film, $1 \mathrm{mg} \mathrm{cm}^{-2}, 1.33 \mathrm{~g}$ $\mathrm{cm}^{-3}$ ) [40], $\mathrm{F}$ (solvated graphene film, $1 \mathrm{mg} \mathrm{cm}^{-2}$ ) [41], G (solvated graphene film, $152 \mu \mathrm{m}, 0.44 \mathrm{mg} \mathrm{cm}^{-2}$ ) [42], $\mathrm{H}$ (graphene on cellulose, $0.44 \mathrm{mg} \mathrm{cm}^{-2}$ ) [28]. 
a)

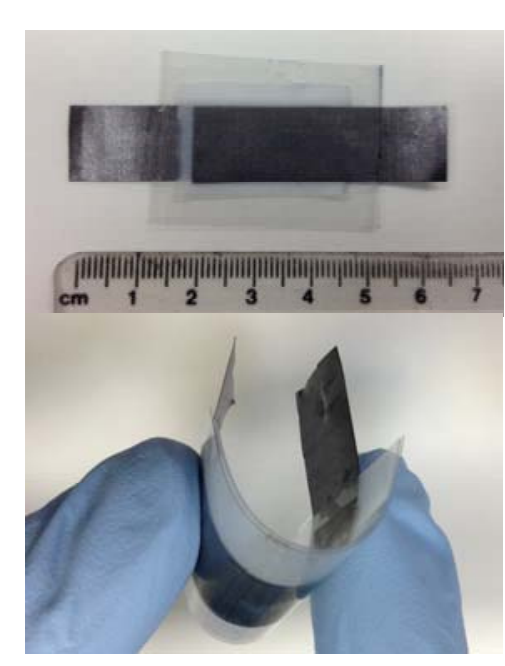

c)

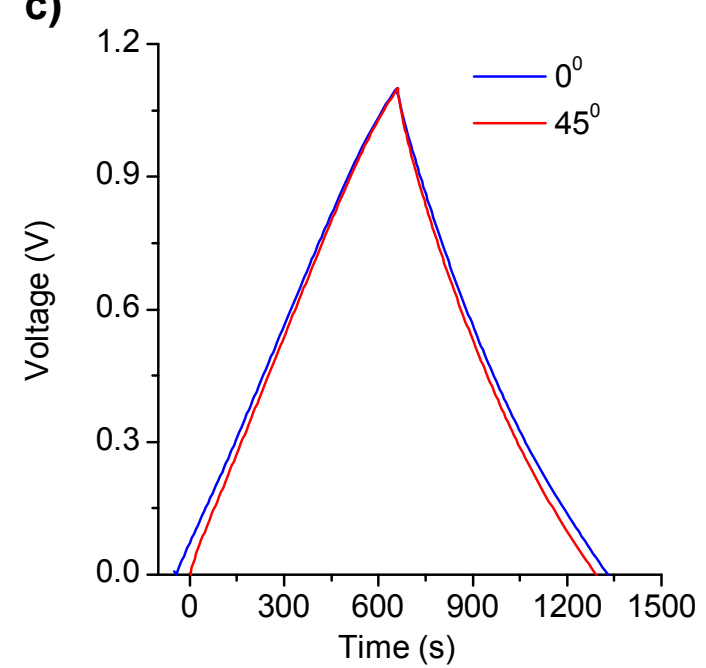

b)

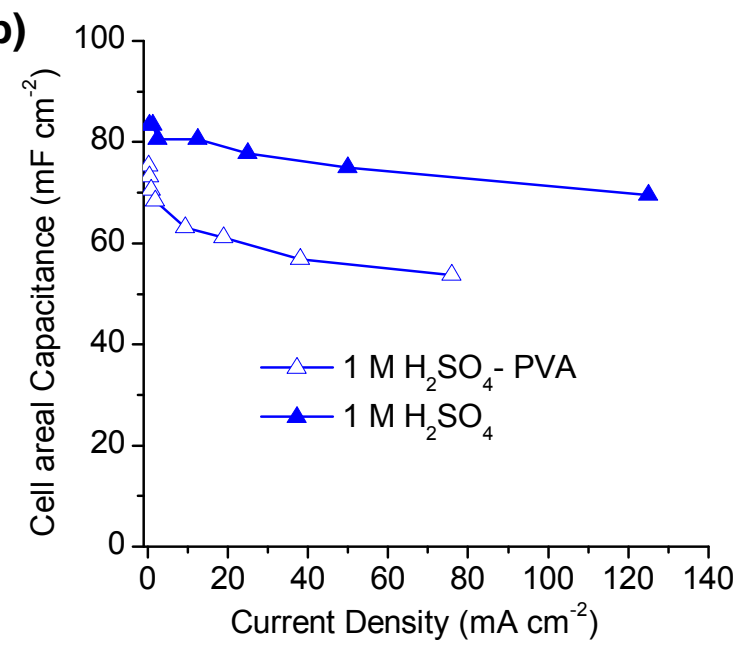

d)

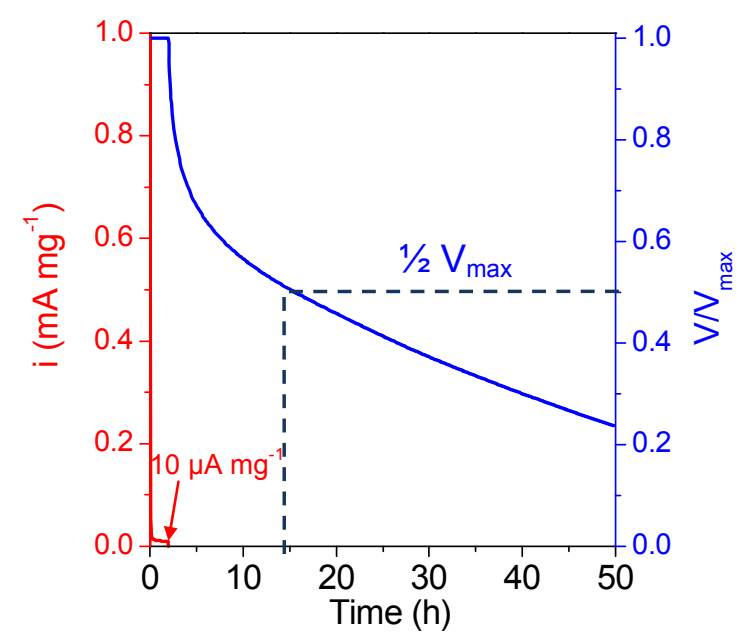

Figure 7. Electrochemical performance of the GT-based solid-state flexible supercapacitor. (a) Image of the flexible solid-state supercapacitor device, (b) variation of the areal capacitance with increasing current density, (c) galvanostatic charge-discharge voltage profiles at $0.2 \mathrm{~mA} \mathrm{~cm}^{-2}$ corresponding to bending angles of $0^{\circ}$ and $45^{\circ}$, and (d) leakage current and self-discharge of the solid-state flexible supercapacitor at a cell voltage of $1.1 \mathrm{~V}$. Electrode material: graphene-tissue composite $\left(1.9 \mathrm{mg} \mathrm{cm}^{-2}\right)$. 